\title{
LA RELACIÓN POLÍTICA \\ SINOESTADOUNIDENSE EN ASIA DEL ESTE: \\ LUCHA POR EL PODER O DIVERGENCIAS \\ RESULTANTES DE LA PERCEPCIÓN \\ DE LA AMENAZA
}

José Jesús Bravo Vergara

EN LA ESCUELA REALISTA, la consideración del poder conformado por el peso de las capacidades materiales constituye la posesión más relevante para los Estados, pues entre más poder material posea un Estado tendrá mayores posibilidades de supervivencia. Asimismo, en el juego de las grandes potencias, William Wohlforth y Kenneth Brooks plantean que con el final de la Guerra Fría y con la desintegración soviética se inició una era unipolar nunca antes vista. ${ }^{1}$ A partir de entonces, Estados Unidos ha quedado como única gran potencia en el mundo con una posición respaldada en las dimensiones del poder, un costo sistémico mínimo capaz de evitar rivalidades, un orden estable motivante del bandwagoning ${ }^{2}$, porque tal orden es pacífico, con probabilidades de durar varias décadas. A partir de este panorama, se puede señalar que Estados Unidos como potencia hegemónica trabaja para mantener el balance en cada región. En estas circunstancias, tanto Wolhlforth como Brooks asumen que, dada la magnitud de sus capacidades, es improbable que Estados Unidos sea balanceado por otra poten-

${ }^{1}$ World Out of Balance: International Relations and the Challenge of American Primacy, Princenton, University Press, 2008, p. 2.

${ }^{2}$ W. Wohlforth, "The Stability of Unipolar World", International Security, vol. 24, núm. 1, 1999, p. 8. 
cia, aun cuando utilice su poder de forma unilateral, ${ }^{3}$ mientras que Robert Kagan señala que el actual statu quo en Asia del Este es tan estable para todos que no hay motivos válidos para que potencias como la República Popular de China (RPCh) se sientan amenazadas. ${ }^{4}$

Sin embargo, las argumentaciones de Wohlforth, Brooks y Kagan dejan de lado una serie de planteamientos concentrados en lo que puede definirse como la percepción de la amenaza, que tiene su base en las identidades estructuradas y las raíces socioculturales domésticas que producen entendimientos surgidos de diferencias de autopercepciones y prácticas, lo que permite que cada Estado se conciba como poseedor de determinados valores que los guían a interpretar su posición en el sistema internacional, así como la posición de otros frente a ellos. Según este argumento, planteo que las acciones de la RPch, desde la reforma de 1978 y, en especial, tras el fin de la Guerra Fría, se han concentrado en continuar su crecimiento sin tener como objetivo competir con Estados Unidos por la hegemonía regional y que sus acciones destinadas a incrementar sus capacidades materiales y a increpar ciertas acciones de este país en la región de Asia del Este se centran en las demandas identitarias del Estado chino de alcanzar la integridad territorial planteada desde su misma fundación en octubre de 1949: continuar con un crecimiento económico seguro y desempeñar un papel de mayor relevancia en su región conforme a su propia percepción histórica de gran nación, objetivos que Washington amenaza.

Este artículo se divide en cuatro apartados. El primero se concentra en una revisión teórica basada en las escuelas realistas: el realismo estructural o neorrealismo y el realismo neoclásico, así también como en el constructivismo, con el fin de establecer una plataforma sustentable para el análisis empírico. El segundo se centra en una breve revisión histórica de la relación política entre ambos países a partir de la misma fundación de la RPch hasta 2014.

${ }^{3}$ Op. cit., pp. 183-200.

${ }^{4}$ The Return of History and the End of Dreams, Nueva York, Alfred Knopf Editors, 2008, p. 99. 
En el tercero se desarrolla un análisis teórico de la actual relación bilateral sinoestadounidense, mientras que en el último apartado se ofrece una conclusión del tema.

\section{REALISMOS ESTRUCTURAL Y NEOCLÁSICO Y CONSTRUCTIVISMO: ENTRE EL PODER, LA IDENTIDAD Y LOS INTERESES}

Desde la perspectiva de las escuelas realistas, el concepto de poder funge como uno de los elementos más debatidos en sus diferentes corrientes. Por ejemplo, si nos remitimos al realismo clásico, hay un argumento según el cual la característica anárquica del sistema internacional crea un ambiente en el que las relaciones entre los diferentes Estados pueden variar conforme a los cambios que sufren en sus respectivas capacidades materiales; cuando hay una concentración de poder en un solo país, el resto de ellos procurará buscar la manera de equilibrarlo. ${ }^{5}$ Kenneth Waltz, el padre del realismo estructural o neorrealismo, señala que los Estados, sobre todo, buscan defenderse a sí mismos, toda vez que la ausencia de una autoridad central suscita incertidumbre. ${ }^{6}$ Asimismo, Waltz señala que ante un ambiente de desconfianza, el poder concentrado en un solo actor conduce inevitablemente a un equilibrio de poder en su contra, porque regularmente este tipo de actores se asigna demasiadas tareas más allá de sus fronteras e intenta imponer su visión de bienestar y justicia, provocando con ello gran preocupación en el resto de los actores del sistema internacional. ${ }^{7}$

Desde una perspectiva del realismo neoclásico, William Wohlforth plantea tres proposiciones esenciales por considerar respecto al poder en el orden internacional vigente. El primero de ellos se centra en el señalamiento de que actualmente hay un "sistema unipolar" protagonizado por Estados Unidos, que disfruta de una

${ }^{5}$ H. J. Morgenthau, Politics Among Nations: The Struggle for Power and Peace, Nueva York, A. A. Knopf, 1948, pp. 21, 23, 63 y 64.

6 Teoría de la política internacional, trad. de Mirta Rosenberg, Buenos Aires, Grupo Editor Latinoamericano, 1988, p. 96.

7 “Structural Realism after Cold War", International Security, vol. 25, núm. 1, 2000, p. 28. 
superioridad económica, militar, tecnológica y geopolítica: los componentes básicos del poder que, por cierto, supone que son incomparables. ${ }^{8}$ En su segunda proposición, junto con Kenneth Brooks, sostiene que la ventaja que le da la magnitud de su poder, en términos de mera capacidad material, es que evita que se presenten grandes conflictos porque ningún Estado está en condiciones de competir o rivalizar con su liderazgo en el sistema internacional. ${ }^{9}$ La última proposición se refiere a que la unipolaridad estadounidense no sólo es pacífica sino durable, pues en su frontera terrestre goza de vecinos sosegados como México y Canadá, así como de cierta protección geográfica que le brindan las fronteras marítimas en el Atlántico y en el Pacífico. ${ }^{10}$

Lo notable del realismo neoclásico es que, a la inversa de los clásico y estructural, las proposiciones desarrolladas por Wohlforth y Brooks se concentran en la negación de que la simple reunión de poder en un solo Estado haga que los demás procuren la manera de equilibrarlo. Según estos autores, en el actual sistema internacional (de característica unipolar), las demás potencias se sienten seguras, porque este sistema es mucho más estable y ello las motiva al bandwagoning, es decir a seguir al Estado preponderante. ${ }^{11}$ Esto no implica el rechazo a la preponderancia de las capacidades materiales; en todo caso, se resalta la posesión de dicha preponderancia de capacidades de parte de un Estado, porque precisamente es esta característica la que evita que haya un contrabalance.

Wohlforth ha señalado que, a pesar de la unipolaridad, este sistema puede considerarse como del tipo que sufre de gran fragilidad; esta idea ha sido motivada porque se ignoran los elementos para crear equilibrio en un contexto real. ${ }^{12}$ Como se señaló antes, Waltz sostiene que cuando hay cierta concentración de poder en un solo Estado, no pasa mucho tiempo antes de que haya un equilibrio de poder en su contra, y si un solo Estado no tiene las sufi-

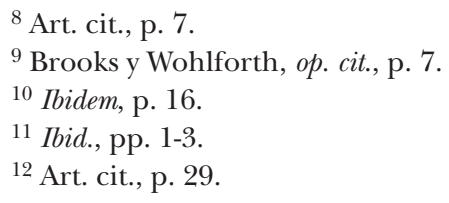


cientes capacidades como para desarrollar este balance, entonces se pueden conformar alianzas para lograrlo. Sin embargo, Wohlforth señala que las alianzas no son estructurales; en todo caso, son coyunturales y tal situación plantea que estas posibles alianzas son menos efectivas que los propios Estados para producir el despliegue de su poder. ${ }^{13}$ En un contexto como el actual, Wohlforth acepta que en un sistema internacional de característica unipolar el balance de poder es imposible y que cuando el contrabalance se presenta es porque este sistema internacional no es unipolar. ${ }^{14}$ En el caso de Estados Unidos, S. G. Brooks y Wolhforth sostienen que quienes pudieran fungir como retadores potenciales, China, Japón, Rusia o Alemania, se oponen los unos a los otros ${ }^{15}$ y, por tanto, es improbable que se produzca un polo que realmente balancee su poder.

Como se ha visto líneas arriba, la perspectiva realista manifiesta la relevancia incuestionable del poder -capacidades materiales, en especial el poder militar- de los Estados como la razón central para el establecimiento de un orden internacional. En el caso del realismo estructural o neorrealismo, lo hace conforme a la premisa de que un sistema sin balance de poder se vuelve conflictivo. Desde la perspectiva del realismo neoclásico, el planteamiento se concentra en el hecho de que el orden internacional actual se ha de conservar, porque la potencia hegemónica -Estados Unidosdetenta tanto poder que ningún país se atrevería a desafiar su supremacía y, por tanto, el orden propuesto por el hegemón ha de prevalecer por muchos años.

Sin embargo, en el sistema internacional, además de la consideración del poder en términos de capacidades materiales, es necesario tener en cuenta la existencia de diversas características de los diferentes actores, tales como los intereses y las identidades de los Estados, así como la interacción entre los diferentes actores en este sistema, lo que hace del mundo un lugar mucho más complejo

\footnotetext{
13 Idem.

${ }^{14} \mathrm{Id}$.

15 “American Primacy in Perspective”, Foreign Affairs, vol. 81, núm. 4, 2002,
} p. 24. 
de lo que a simple vista se plantea a partir de la escuela realista en general.

Desde un enfoque diferente al de la propuesta meramente racionalista que representa la corriente realista, el constructivismo, a partir de lo ontológico y lo epistemológico, propone la necesidad de desarrollar mayor entendimiento acerca de una realidad externa cognoscible, lo que implica que no sólo se concentra en el análisis único de lo material, sino, sobre todo, en lo social. Por esta razón se plantea que esta perspectiva se concentra en el análisis de cómo lo material del mundo subjetivo e intersubjetivo -aquello subyacente en lo que a simple viste se observa- interactúa en la construcción social de la realidad. ${ }^{16}$

En relación con esta idea, Arturo Santa Cruz señala que en el enfoque constructivista, las realidades material y social no están diferenciadas de forma contundente por la consideración de que ambas están intrínsecamente correlacionadas. ${ }^{17}$ Esto implica que la "interpretatividad" del constructivismo conlleva la negación de que las teorías puedan ser validas únicamente si éstas se adecuan a los eventos que se presentan en la realidad externa. Con todo, aun así toma en cuenta la existencia de una realidad externa generadora de la acción social. Según este planteamiento, y sin dejar de considerar la relevancia de las capacidades materiales, esta perspectiva conceptualiza el poder no sólo desde el punto de vista de competencia material, sino como la habilidad y el talento en sí para obtener resultados favorables por parte de un Estado o un actor.

El constructivismo no centra su discusión en la lucha por el poder como lo señalan en la escuela realista. John Gerard Ruggie argumenta que el primer impulso constructivista es incorporar valores como las identidades, las normas y los significados en el estudio de las relaciones internacionales. ${ }^{18}$ Asimismo, desde esta perspectiva,

${ }^{16}$ Cf. E. Adler, "Seizing The Middle Ground Constructivism in World Politics”, European Journal of International Relations, vol. 3, núm. 3, 1997, p. 330.

${ }^{17}$ Un debate teórico empíricamente ilustrado: la construcción de la soberanía japonesa, 1853-1902, Guadalajara, Universidad, 2000, p. 164.

18 Constructing the World Polity: Essays on International institutionalization, Londres-Nueva York, Routledge, 1998, pp. 37-39. 
se evoca la visión de que los "factores ideacionales" se han tomado por norma en cuanto que dimensiones instrumentales que se expresan, no sólo en una intención individual, sino también colectiva. Ruggie recalca que las características distintivas del constructivismo están en el ámbito ontológico, el fenómeno del mundo real que está determinado por alguna teoría e invocada por sus explicaciones. ${ }^{19}$

En el ámbito de actores individuales, el constructivismo busca, en primera instancia, la problematización de las identidades y los intereses de los Estados para mostrar "qué" y "cómo" se elaboran socialmente. Alexander Wendt señala que las identidades son conceptualizaciones específicas del papel y las expectativas que tienen los actores -incluidos los Estados- acerca del "yo" relativamente estables. ${ }^{20}$ Wendt también señala que en el caso de los Estados, éstos pueden tener múltiples identidades, como ser la hegemonía, tal y como sucede con Estados Unidos, o ser considerado el "Reino de Centro", ${ }^{21}$ una asunción histórica que China había desarrollado en sí misma.

Arturo Santa Cruz argumenta que las identidades no son estáticas ni tienen esencia, pero se consolidan mediante la acción social y tienen que ser investigadas en entornos contextuales históricos específicos. ${ }^{22}$ Por su parte, Ted Hopf señala que las identidades de un actor (el Estado) conforman una variable que depende de los contextos histórico, cultural, político, social y hasta geográfico, lo que implica que se trata del rasgo fundamental de cada Estado y generan acción tanto en el interior como en el exterior. ${ }^{23}$ Asimismo, de manera coloquial menciona que las identidades plantean tres funciones necesarias en la sociedad: te dicen a ti

${ }^{19} \mathrm{Id}$.

20 "Anarchy is what States Make of it: The Social Construction of Power Politics”, International Organizations, vol. 46, núm. 2, 1992, p. 397.

${ }^{21}$ Cf. J. Zhang, "China's new Foreign Policy under Xi Jinping: towards «Peaceful Rise 2.0»”, Pacifica Review: Peace, Security E̋ Global Change, vol. 27, núm. 1, 2013, pp. 5-6.

22 Op. cit., p. 174.

23 "The Promise of Constructivism in International Relations Theory", International Security, vol. 23, 1998, p. 193. 
mismo y a otros quién eres y también te dicen quiénes son los otros. ${ }^{24} \mathrm{Al}$ decirte quién eres, las identidades reflejan un conjunto de intereses y preferencias respecto a las elecciones que un Estado realiza para ejecutar sus acciones. Del mismo modo, las identidades reflejan la posición de éste frente a los demás y permiten la percepción acerca de la posición de los demás frente a él.

Mlada Bukovansky argumenta que la identidad está conformada según las bases o los principios que determinan el papel de un Estado en el sistema internacional, que tales principios permiten a los diferentes grupos o corrientes coincidir alrededor de un fin común que puede articularse como colectivo y convertirlo en nacional y que la identidad no es estática, es decir que ésta puede ser rebatida o replanteada. ${ }^{25}$

La explicación de los párrafos anteriores tiene su base en el planteamiento desarrollado por Wendt en referencia a las metas y elecciones que los Estados hacen. Las identidades son la base de los intereses, en este caso, de los intereses nacionales. ${ }^{26} \mathrm{Si}$ tomamos en cuenta este argumento, Jutta Weldes señala que los intereses nacionales son un tema central en el estudio de las relaciones entre los países. ${ }^{27}$ Sin embargo, es necesario señalar que los Estados no traen un paquete inherente y específico de intereses desde el momento en que son conformados, pues tal y como lo señala Weldes, los intereses son construcciones sociales creadas por los Estados como objetos que producen una serie de significados intersubjetivos y culturalmente establecidos con los que el sistema internacional es comprendido, al tiempo que explican el lugar que este Estado ocupa en la estructura del sistema. ${ }^{28} \mathrm{La}$ identidad puede entenderse entonces como el cimiento o la base que origina la acción social o política. ${ }^{29}$

${ }^{24}$ Ibid., p. 174.

25 "American Identity and Neutral Rights from Independence to the War of 1812”, International Organization, vol. 51, núm. 2, 1997, p. 217.

${ }^{26}$ Art. cit., p. 398.

27 "Constructing National Interest", European Journal of International Relations, vol. 2, núm. 3, 1996, p. 275.

${ }^{28}$ Ibid., p. 280.

${ }^{29}$ R. N. Lebow, "Identity and International Relations", International Relations, vol. 22, núm. 4, 2008, p. 474. 
En suma, la identidad antecede a los intereses de los actores, lo que un actor busca o desea que se desarrolle según la percepción que se tiene de sí mismo y, con ello, se establece que los intereses de los Estados, así como sus identidades, no están insertos de forma inherente, sino que se crean y se van desarrollando por medio de un proceso de interacción social. A su vez, los intereses, que también son producidos por medio de las prácticas sociales, igualmente son de suma importancia, porque por ellos se hace posible la funcionalidad del concepto de identidad. ${ }^{30}$

Es precisamente la explicación acerca de la identidad la que nos permite realizar una serie de cuestionamientos de los dirigentes de los países sobre quién representa una amenaza para sus respectivos Estados. Desde ese punto de vista, los constructivistas difieren en cuanto a los parámetros que manejan los seguidores de las escuelas realistas, quienes plantean que el ambiente de los Estados puede concebirse y apreciarse únicamente según la capacidad material, ya sea como lo señalan los realistas clásicos y neorrealistas, quienes destacan que por el ambiente anárquico del sistema internacional, la acumulación de poder por parte de un Estado supone, en sí misma, una amenaza directa para otros y por ello produce un balance de poder en su contra, o en el supuesto contrario de la escuela realista desarrollado por Wohlforth y Brooks acerca de que la concentración de poder material en el actual hegemón -Estados Unidos- es tal, que no hay posibilidad de equilibrarlo y, por tanto, no hay una amenaza real de transformar el actual orden internacional, el cual le es favorable.

Para los constructivistas, la anarquía y la distribución de poder son insuficientes para explicar la existencia de una amenaza. ${ }^{31}$ Lo anterior es respaldado por la visión de Hopf, quien sugiere que los Estados no buscan el equilibrio contra el simple poder, sino que lo hacen contra tipos particulares de poder. ${ }^{32}$ Algunos constructivistas han evidenciado el equilibrio de poder como una de las corrientes principales que explican con más susceptibilidad su

\footnotetext{
${ }^{30}$ Cf. A. Santa Cruz, op. cit., p. 175.

${ }^{31}$ Cf. A. Wendt, art. cit., p. 397.

${ }^{32}$ Art. cit., pp. 186-187.
} 
alternativa. Sin embargo, lo que aquí nos compete es identificar lo relativo a la percepción de la amenaza, algo que propone la explicación constructivista de identidad. ${ }^{33}$

Según estas consideraciones es preciso desarrollar una serie de cuestionamientos acerca de la interacción política sinoestadounidense en Asia del Este que nos permita plantearnos explicaciones que pueden ir desde la competencia directa por la hegemonía entre ambas potencias hasta el entendimiento de que, a causa de sus respectivas identidades, ${ }^{34}$ la relación entre Washington y Pekín encuentra puntos de choque que se vuelven de gran relevancia por la magnitud de sus capacidades materiales y sus alcances respecto al interés de alcanzar metas derivadas de su propia percepción identitaria.

Para sentar las bases del entendimiento de la relación política sinoestadounidense es preciso recurrir a la exploración histórica a partir del ascenso estadounidense como potencia hegemónica, el inicio de la Guerra Fría, la fundación de la República Popular de China, el acercamiento de ambas potencias en la década de 1970 y las divergencias que de forma constante se han presentado en los últimos años, así como los motivos que los han causado.

\section{LA RELACIÓN HISTÓRICO-POLÍTICA SINOESTADOUNIDENSE}

A PARTIR DE LA FUNDACIÓN DE LA RPCH: TAIWÁN, LA PENÍNSUla de CoREA Y LA CUESTIÓN ECONÓMiCA

El triunfo de los comunistas y la fundación de la República Popular de China en octubre de 1949 planteó una gran disyuntiva para Estados Unidos, porque la caída de los nacionalistas en la China continental representó la pérdida de un aliado potencial en el Lejano Oriente en pleno inicio de la Guerra Fría con la Unión Soviética. ${ }^{35}$

$33 I d$.

${ }^{34}$ Me refiero a la identidad de potencia hegemónica por parte de Estados Unidos y a la de potencia que busca un orden multilateral que le permita alcanzar sus propósitos en el caso de la RPch.

35 Tanto la victoria del Partido Comunista en China (PCCh), como la posesión del arma nuclear soviética representaron un verdadero dilema para Estados Unidos, porque ambos acontecimientos sumaban una gran fuerza en lo que Washington 
En el asunto de Taiwán, los nacionalistas chinos liderados por Chiang Kai-shek huyeron a la isla de Formosa (Taiwán), donde implantaron un gobierno que fue reconocido por Washington y por otros países aliados como único representante del pueblo y del Estado chinos. A su vez, el régimen de Mao Tse Tung instaurado en el continente fue reconocido solamente por el bloque comunista y por otros pocos países de modesta influencia internacional.

Además de otorgar su reconocimiento al régimen de Chiang Kai-shek, el gobierno de Estados Unidos frustró constantemente los planes comunistas de invadir la isla por medio del envío de fuerzas navales y mantuvo la idea de que un gobierno nacionalista chino en Taiwán podría alentar una oposición proestadounidense en el continente y la posibilidad de derrotar a Mao Tse Tung. Sin embargo, los estadounidenses tuvieron que conformarse con la defensa territorial del gobierno nacionalista chino asentado en Formosa ante la amenaza de la expansión comunista.

La irrupción de la guerra en Corea en 1950 provocó un nuevo motivo de confrontación entre ambos países, ya que en su afán por aniquilar a las fuerzas norcoreanas, las tropas de la onU lideradas por Estados Unidos llegaron hasta la frontera con el territorio chino y generaron una percepción de amenaza en el régimen de Pekín. El entonces ministro de Relaciones Exteriores de la RPCh, Zhou En-lai señaló que el asunto de Corea había reemplazado en ese momento a Formosa como el motivo más urgente de atención exterior por su trascendencia en la propia seguridad de la RPCh, ${ }^{36}$ por lo que se dispuso a intervenir en favor de los norcoreanos, pero conforme al argumento de que las tropas chinas eran voluntarias. ${ }^{37}$ Finalmente, tras un estancamiento en sus posiciones y el peligro de una conflagración aún mayor, la guerra se detuvo por

identificaba como amenaza conjurada de expansión comunista. Véase Ch. Jian, China's Road to the Korean War: The Making of the Sino-American Confrontation, Nueva York, Columbia University Press, 1994, p. 126.

${ }^{36}$ H. C. Hinton, La China comunista en la politica mundial, trad. de Ramón F. Martel, México, Unión Tipográfica Editorial Hispano Americana, 1968, pp. 264-265.

${ }^{37}$ J. L. Gaddis, Nueva Historia de la Guerra Fría, México, Fondo de Cultura Económica, 2011, p. 64. 
medio de una tregua el 27 de julio de $1953 .{ }^{38}$ Los costos de la guerra confirmaron la desconfianza entre ambos países, por tal motivo Estados Unidos continuó obstaculizando la entrada de la RPCh en el seno de la ONU.

El final de los combates en la península de Corea reanudó la atención del conflicto entre la RPch y el régimen nacionalista chino estacionado en Taiwán y ello produjo dos momentos de tensión entre 1954 y 1958 por causa de los ejercicios militares de la "China continental". La primera crisis motivó la firma de un Tratado de defensa mutua entre Estados Unidos y la entonces llamada República de China (Taiwán), el 2 de diciembre de 1954. ${ }^{39}$ Mientras que la segunda produjo tal preocupación en la URss, que el entonces líder soviético, Nikita Kruschev, a pesar de mostrar en público su respaldo al gigante asiático frente a una posible intervención estadounidense, criticó en privado las acciones de Pekín como una provocación innecesaria, al tiempo que quedó persuadido de transferir tecnología nuclear a la RPCh. ${ }^{40}$ Ésta fue una de las múltiples razones del rompimiento que años depués se daría entre los dos gigantes socialistas.

$\mathrm{Al}$ argumento de Pekín con respecto de su política hacia el gobierno estacionado en Taiwán correspondería un alegato con-

${ }^{38}$ Ch. Jian, China en transición. Sociedad, cultura y economía, Barcelona, Bellaterra, 2000, p. 401.

${ }^{39}$ A. I. Johnston, "Cultural Realism and Strategy in Maoist China”, en Peter Katzenstein, The Culture of National Security: Norms and Identity in World Politics, Nueva York, Columbia University Press, 1996, p. 3.

${ }^{40}$ Ante la movilización de la séptima flota y la posibilidad de apoyo británico, el entonces líder del Kremlin, Nikita Khruschev, replicó que cualquier ataque a la RPch se consideraría como una agresión a la Unión Soviética, lo que disuadió a Estados Unidos de hacer efectivas sus amenazas de represalia. Sin embargo, los líderes soviéticos criticaron en privado que la acción china era una provocación innecesaria que debió consultarse con Moscú. Asimismo, advirtieron que no ayudarían a la RPCh en caso de que la crisis provocada por los chinos comunistas condujera a la guerra. Esta situación comenzó, por tanto, a distanciar a los dos gigantes comunistas. Véase "Second Taiwan Strait Crisis Quemoy and Matsui Islands", en http://www.globalsecurity.org/military/ops/quemoy_matsu-2.htm, y E. Anguiano, "Diplomacia de la República Popular China", en E. Anguiano (coord.), China contemporánea. La construcción de un país (desde 1949), México, El Colegio de México, 2001, p. 227. 
siderado como un principio identitario del nuevo Estado chino: su derecho a alcanzar su integridad territorial y lograr su soberanía en aquellos territorios que considera como propios. Este planteamiento fue utilizado en 1950, cuando ocupó y anexó el Tíbet con el argumento de recuperar lo que denominó "la soberanía histórica" en esa región autónoma, ${ }^{41}$ cuando entró en guerra con India en 1962 y le arrebató la zona de Aksai-Chin ${ }^{42}$ y cuando, en marzo de 1969, el ejército chino protagonizó una sangrienta escaramuza en Zhembao contra los guardias soviéticos durante las tensiones fronterizas en las orillas de los ríos Ussuri y Amur, ${ }^{43}$ con la demanda de que le fueran devueltas decenas de islas que los soviéticos habían ocupado en el interior de ambos ríos. ${ }^{44}$

La idea de Pekín de alcanzar su integridad territorial proponía la necesidad de delinear oficialmente las fronteras de la RPCh como

41 Cf. J. Powers, 2004, History as Propaganda: Tibetian Exiles Versus the People's Republic Of China, Nueva York, Oxford University Press, 2004, p. 111. Hacia el año de 1644, los manchúes del norte conquistaron el imperio chino de los Ming y establecieron la dinastía Qing. La dinastía Manchú consolidó su relación con el Tíbet y envió ejércitos tanto para proteger a los tibetanos, como para asegurar su posición geopolítica frente a las pretensiones expansionistas de mongoles y dzhungaros. La presencia de la administración del imperio chino en el Tíbet plantea una relación de dominio virtual sobre esta nación a pesar del respeto de su autonomía. Véase R. Arroyo Velasco y G. Pérez Gavilán "El conflicto chino-tibetano desde la perspectiva de la ética en Relaciones Internacionales”, Revista de Relaciones Internacionales de la UNAM, núm. 91, 2003, p. 61.

${ }^{42}$ Aksai-Chin es una zona en el margen oriental de la línea McMahon, línea fonteriza impuesta por el imperio británico a principios del siglo xx y que India había conservado tras su independencia en 1947. La guerra sinoindia, que comenzó el 20 de octubre de 1962, terminaría un mes después con el triunfo del ejército chino y el control de la zona reclamada por Pekín. Véase M. Y. Prozumenschikov, "The Sino-Indian Conflict, the Cuban Missile Crisis, and the Sino-Soviet Split, October 1962: New Evidence from the Russian Archives", Cold War International History Project Bulletin, 1996-1997, pp. 251-257, y E. Anguiano, art. cit., p. 231.

${ }^{43}$ M. S. Gerson, "The Sino-Soviet Border Conflict: Deterrence, Escalation, and the Threat of Nuclear War in 1969, Defense Threat Reduction Agency Advanced Systems and Concepts Office”, Report Number ASCO, 2010 027, Contract Number NOOO14-05-D-0500, 2010.

${ }^{44}$ H. Gelman, "The Soviet Far East Buildup and Soviet Risk-Taking Against China”, A project AIR FORCE report prepared for the United States Air Force, The Rand Corporation, R-2943-AF, agosto de 1982, p. 50. 
una forma de ganar legitimidad tanto en el interior frente a sus ciudadanos como en el exterior frente a la sociedad internacional, ${ }^{45}$ por tal motivo debía solucionar a su favor las querellas resultantes de los llamados acuerdos desiguales que las potencias europeas y Japón le impusieron durante la segunda mitad del siglo xIx, incluso a través de la guerra. Asimismo, si bien es cierto que tuvo éxito en la mayoría de sus reclamos, el tema de la soberanía china sobre de Taiwán continuó siendo el principal foco de atención del régimen chino.

La década de 1970 resultaría ser una etapa de apaciguamiento entre la RPch y Estados Unidos, ya que Washington aprovechó el alejamiento entre Pekín y Moscú para acercarse al gigante asiático y lograr que se diera la visita a la capital de la China continental del entonces presidente estadounidense, Richard Nixon, en febrero de 1972. ${ }^{46}$ Para ese entonces, la representación de la RPch ya había sido aceptada como única representante del pueblo y Estado chinos en la Organización de Naciones Unidas al tiempo que había sido expulsada la representación de la República de China. ${ }^{47}$ El acercamiento sinoestadounidense tenía como premisa dos consideraciones claras: el establecimiento del régimen de Pekín de que Taiwán es parte integral del territorio chino, mientras que de parte de Washington se planteaba la consideración de "un código diplomático" concentrado en el interés estadounidense de una solución pacífica con respecto de la posible incorporación de Taiwán a la RPch y que, dado ese compromiso, debía disuadir cualquier intento del ejército chino de tomar la isla por la fuerza. ${ }^{48}$

La regularización de la relación diplomática entre Estados Unidos y la RPCh pudo llevarse a cabo hasta 1979. Para entonces, Mao

45 A. D. Abidol, "Causes of the 1962 Sino-Indian War", Josef Korbel Journal of Advanced International Studies, vol. 1, 2009, p. 80.

${ }^{46}$ A. J. Nathan y A. Scobell, "How China Sees America”, Foreign Affairs, septiembre-octubre de 2012, pp. 32-47.

${ }^{47}$ En octubre de 1971, por propuesta de Albania en la resolución 2758 de la Asamblea General de las Naciones Unidas, la RPch fue aceptada como representante del pueblo y Estado chinos, mientras que la República de China fue expulsada. Véase E. Anguiano, art. cit., p. 242.

${ }^{48}$ A. J. Nathan y A. Scobell, art. cit., pp. 36-40. 
Tse Tung ya había fallecido y la RPch era gobernada por Deng Xiaoping, un hombre con una visión centrada en la reforma económica y comercial china, mientras que Estados Unidos era gobernado por el demócrata Jimmy Carter, quien aceptaba la determinación de Pekín de que había una sola China y de que Taiwán era parte integral de ésta. A partir de la década de 1980, Pekín y Washington aumentaron los vértices de sus relaciones y comenzaron a cooperar tanto en lo comercial como en materia de espionaje durante la invasión soviética a Afganistán. ${ }^{49} \mathrm{El}$ incremento de la presencia diplomática china en Asia del Este coincidía con la idea estadounidense de dar estabilidad en la región y por ello configuraba una suma positiva de interacciones entre Washington y Pekín en un momento en que la retracción soviética planteaba la posibilidad de que se produjera un nuevo escenario internacional.

Los cambios instrumentados por Mikhail Gorbachov en la urss a partir de su ascenso como líder del Partido Comunista, en 1985, produjeron para la RPCh dos efectos inmediatos fundamentales: la aceptación de Moscú de negociar de forma satisfactoria el margen medio de los ríos Amur y Ussuri como frontera entre ambos países ${ }^{50}$ y una serie de protestas estudiantiles que demandaba al régimen de Pekín una apertura similar a la que por entonces se estaba dando en Moscú. Esas protestas fueron reprimidas en la Plaza de Tiananmen, en 1989, por el gobierno chino, una acción ampliamente criticada desde Washington. ${ }^{51}$

La década de 1990 trajo el planteamiento de un nuevo escenario internacional en dos vértices. Por un lado, la desintegración soviética y las posibilidades para Estados Unidos y la RPCh de explorar nuevas relaciones con los países de Asia Central y el Cáucaso, así como el incremento del comercio entre Washington y Pekín que produjo una balanza comercial en favor del gigante asiático. Por otro, la relación sinoestadounidense se vio afectada de nueva

49 E. Forigua-Rojas, "Guerra en Afganistán: la experiencia soviética”, Papel Político, vol. 15, núm. 1, 2010, p. 213.

${ }^{50}$ J.-dong Yuan, "Sino-Russian Confidence building Measures: A Preliminary Analysis”, Working Paper No 20, enero de 1998, p. 3.

${ }^{51} \mathrm{~J}$. Mann, A History of America's Curious Relationships with China, from Nixon to Clinton, Nueva York, Vintage Books, 1998, p. 181. 
cuenta por causa de una nueva tensión originada por la apertura democrática en Taiwán y el triunfo en la dirección del gobierno taiwanés de Lee Teng-hui, quien además de impulsar la democratización en la isla fomentó una postura independentista aludiendo que Taiwán ya no tenía más la pretensión de representar a toda China y que, en todo caso, la reunificación dependería de la armonización del sistema político en ambos lados del estrecho, es decir de la democratización de China. ${ }^{52}$ Esta posición planteó un rechazo implícito a la fórmula de "un país, dos sistemas" 53 que Pekín acordó con Hong Kong, cuando la antigua colonia británica regresó a su soberanía en 1997.

La política interna de Lee Teng-hui permitió el incremento en los escaños del gobierno de la isla por parte de las élites proindependentistas representadas en diversos partidos que rechazaban cualquier tipo de unión con la "China continental", 54 ante airadas protestas del gobierno de Pekín, que comenzó a instrumentar una serie de maniobras militares en marzo de $1996 .{ }^{55}$ Washington señaló que no toleraría el uso de la fuerza ni la violación a la integridad taiwanesa, por lo que movilizó un par de portaviones al tiempo que renovó su alianza militar con Japón en 1996. ${ }^{56}$

La posición de Estados Unidos planteó a los dirigentes chinos la necesidad de reconsiderar sus relaciones con otras potencias, en especial con Rusia y, hacia 1996, los dirigentes de la RPch y Rusia, así como los de Kazajstán, Tayikistán y Kirguistán sostuvieron en Shanghai una reunión que sería conocida como "Los 5 de Shanghai"

52 “Taiwan Strait I: What's Left of «One China»", ICG Asia Report No 53, Beijing/Taipei/Washington/Brussels International Crisis Group, 6 de junio de 2003, p. 12.

${ }^{53}$ El principio de "un país, dos sistemas" se empleó desde la década de 1970 y fue dirigido, en una primera instancia, para resolver la cuestión de Taiwán.

${ }^{54}$ El avance del Partido Democrático Progresista, el cual recibió apoyo de las fuerzas políticas menores, como el Partido de la Independencia de Taiwán y el Partido de Unificación de Taiwán, produjo nuevos desencuentros entre la RPch y Taiwán. Véase H. Jing y L. Xiaoting, "China’s Taiwan Policy: Dilemma and Choice”, Pacific Focus, vol. 16, núm. 2, 2001, p. 105.

55 Taiwan Today, 28 de marzo de 1996.

${ }^{56}$ E. Anguiano, "Seguridad regional en Asia Pacífico", Anuario Asia Pacífico, núm. 4, 1997, p. 61. 
y que serviría como base para que en 2001 anunciaran el establecimiento oficial de la Organización para la Cooperación de Shanghai (OCS). ${ }^{57}$

No obstante la desconfianza mutua por la situación en el estrecho de Taiwán, Corea del Norte fue el motivo de una nueva preocupación común en el Noroeste de Asia tras poner en marcha un ambicioso programa nuclear con fines militares que planteaba un peligro directo para Corea del Sur y Japón. La gran influencia de Pekín con respecto de Pyongyang sugirió a Washington la necesidad de incluir a la RPCh frente a esta nueva amenaza regional y con ello se facilitó la comunicación entre Estados Unidos y Corea del Sur, por un lado, y Corea del Norte, por el otro, en lo que se conoció como las "Pláticas de las Cuatro Partes", celebradas entre diciembre de 1997 y marzo de $1998 .{ }^{58}$ Así, el régimen chino tuvo un importante logro diplomático al asumir un papel de garante para la estabilidad en Asia del Este.

Una vez tratada la problemática en la península coreana, el asunto de Taiwán retomó su posición como el tema más delicado de la agenda bilateral sinoestadounidense. Asimismo, a pesar de que Washington nunca dejó de mantener canales de comunicación abiertos con Taipei, durante una visita de Estado a la RPch entre junio y julio de 1998, el presidente Clinton enunció en una librería de Shanghai, ante un grupo de intelectuales chinos, su declaración sobre los Three-No's acerca de Taiwán: no a la independencia de Taiwán, no a la existencia de "dos Chinas" o de "una China” y "un Taiwán” y no a la membresía de Taiwán en cualquier organización para la que la condición de Estado fuese un requisito. ${ }^{59}$ Sin embargo, el bombardeo de la embajada china en Belgrado durante la intervención de la otAN en Kosovo en marzo de

${ }^{57}$ K. J. N. Oest y P. Toft, "The Shanghai Cooperation Organization- A Threat or Opportunity for Europe?”, Institut for Statskundskab, 2007.

${ }_{58}$ H.-S. Shin, "U.S.-Japan Security Relations and the Politics of Northeast Asia”, Asian Perspective, vol. 20, núm. 2, 1996, p. 95.

${ }^{59}$ V. Wie-cheng Wang, "Bill Clinton's «Three Noes» and Taiwan's Future”, en Winston L. Yang y Deborah A. Brown (eds.), Across the Taiwan Strait: Exchanges, Conflicts and Negotiations, Jamaica, NY, Center of Asian Studies, St. John's University, 1999, p. 258. 
1999 afectó de nueva cuenta las relaciones entre ambos países durante los últimos meses de la administración de Clinton. ${ }^{60}$

El ascenso del republicano George W. Bush a la presidencia de Estados Unidos trajo como consecuencia nuevos motivos de discordia en la relación bilateral, en especial por causa del incidente del avión espía estadounidense en Hainan en la primavera de 2001 y la venta de armas de última tecnología a Taiwán por parte de Washington. ${ }^{61}$ Asimismo, Bush Jr. redefinió la relación de Estados Unidos con la RPCh como la de una "competencia estratégica" y con su discurso afectó la percepción de los líderes chinos. Del mismo modo, cuando Pekín apoyó en su inicio la guerra contra el terrorismo que lanzó tras el 11/09 contra los talibanes en Afganistán y proporcionó información al Pentágono, ${ }^{62}$ lo hizo con la idea de asumir el papel de actor responsable en el orden internacional ${ }^{63} \mathrm{y}$ dejó en claro su postura de que el tema sobre Iraq debía ser resuelto por medios diplomáticos y políticos en el marco legal del Consejo de Seguridad de Naciones Unidas. ${ }^{64}$ Esta situación planteó un nuevo desencuentro y, con ello, la relación bilateral se fue desgastando de forma progresiva, pues las acciones unilaterales de Estados Unidos causaron suspicacia en Pekín.

En su visión de seguridad, la administración de George W. Bush continuó demandando a la RPCh mayor cooperación en la lucha contra el terrorismo, en particular respecto a los programas nucleares de Corea del Norte e Irán, países a los que, junto a Iraq, calificó como miembros del "Eje del Mal”. El presidente estadounidense demandó de Pekín una posición de guía en un escenario

${ }^{60}$ D. Welch Larson y A. Shevchenko, "Status Seekers: Chinese and Russian Responses to U.S. Primacy”, International Security, vol. 34, núm. 4, 2010, p. 70.

${ }^{61} \mathrm{Ch} . \mathrm{Ou}$, art. cit., p. 104.

${ }^{62}$ El gobierno chino apoyó a Estados Unidos porque interpretó los ataques de Al Qaeda a las Torres Gemelas como una embestida a la dinámica económica mundial, de donde la propia RPch se había beneficiado. Véase B. Garrett, "USChina Relations in the Era of globalization and Terror: A framework for analysis", Journal of Contemporary China, vol. 15, núm. 48, 2006, p. 395.

${ }^{63}$ D. Welch Larson y A. Shevchenko, art. cit., p. 85.

${ }^{64}$ R. Li, "North East Asia”, en Mary Buckley y Robert Sing (eds.), The Bush Doctrine and the War, Terrorism: Global responses, Global consequences, Nueva York, Routdlege, 2006, pp. 76-77. 
internacional encabezado por Washington e incluso el Senado estadounidense replanteó la definición inicial para Pekín de "competidor estratégico" a "participante responsable". ${ }^{65}$ Asimismo, el entonces embajador estadounidense en Pekín, Clark Randt, mencionó que unos lazos fuertes con la RPCh reforzaban el posicionamiento de Estados Unidos. ${ }^{66}$ Sin embargo, sin dejar de poner en evidencia la trascendencia económica y política de la relación bilateral, la RPch junto con Rusia comenzaron a hacer hincapié en la necesidad de un mundo multipolar. ${ }^{67}$

El ascenso de Barack Obama a la presidencia de Estados Unidos trajo consigo una nueva esperanza de un mundo en que la potencia hegemónica precisaría modular y socializar la posición que había desarrollado a partir de su seguridad. Incluso durante la toma de poder, el nuevo presidente estadounidense expresó la necesidad de Estados Unidos de recuperar la influencia perdida. ${ }^{6}$ Sin embargo, en 2007, cuando era uno de los precandidatos demócratas a la presidencia, Obama había señalado que la RPch no era ni amigo ni enemigo de Estados Unidos, sino su competidor. ${ }^{69}$ En este panorama, y a pesar de que durante la administración de Obama se incrementó la magnitud de los intercambios comerciales entre Washington y Pekín, la relación bilateral comenzó a verse afectada por una serie de acciones que plantea no sólo la competencia económica entre ambos países, sino también una nueva serie de pugnas en el ámbito político-diplomático concentrada en Medio Oriente y Asia del Este.

Respecto a Medio Oriente, Estados Unidos ha estado pendiente del conflicto que se desató desde 2011 en Siria, así como del programa nuclear iraní. En el caso del interés chino por ambos países, la RPch y Rusia han frustrado, en el marco del Consejo de Seguridad de Naciones Unidas, diversas propuestas de sanciones y

${ }^{65}$ Ch. Ou, art. cit., p. 104.

${ }^{66} \mathrm{Id}$.

${ }^{67}$ Declaración conjunta de China y Rusia sobre el Orden Internacional en el siglo xxi, 2 de julio de 2005, en www.mfa.gov.cn/esp/zt/hjtfwelssk/t202164.htm.

68 Cf. H. Kissinger, "Obama's Foreign Policy Challenge”, Washington Post, 22 de abril de 2009 .

${ }^{69}$ Ch. Ou, art. cit., p. 104. 
condena al régimen sirio de Bashar $\mathrm{Al}$ Assad por parte de Estados Unidos y sus aliados, con el argumento de que con dichas sanciones sólo se contribuiría a intensificar la actual guerra civil. ${ }^{70}$ Mientras que con respecto a Irán, Pekín se ha opuesto a la intervención o a un incremento de sanciones en su contra por causa del desarrollo de su programa nuclear. La razón es clara: mientras que Irán representa más del 10\% de las importaciones de petróleo para la RPCh, ${ }^{71}$ Siria ha sido de los principales socios comerciales de la RPCh en la región y un país considerado como estratégico para la estabilidad que precisa Pekín en Medio Oriente como nodo en su proyecto de la nueva ruta de la seda. La RPch también se ha interesado en el asunto sirio a causa de la participación de voluntarios uigures de la provincia de Xinjiang como elementos yihadistas del Estado Islámico, una situación que considera peligrosa por la proclividad de éstos al separatismo. ${ }^{72}$ Del mismo modo, los líderes chinos ven una posible intervención estadounidense contra uno o ambos países como la repetición de la invasión a Iraq en 2003, acción considerada como unilateral para obtener mayor control sobre la región más rica en hidrocarburos del mundo y contener al mismo tiempo el acceso chino a los recursos de la región, tan importantes para la continuidad de su crecimiento económico.

En el caso de Asia del Este, las divergencias entre Estados Unidos y la RPCh durante las administraciones del presidente Obama se han centrado en varios rubros; los más relevantes son las cuestiones territoriales, el incremento por parte de Pekín de sus gastos de defensa, la competencia por lograr mayor influencia en la región, así como algunas problemáticas comerciales. En el caso de los reclamos territoriales que hace Pekín, éstos se concentran, aparte de Taiwán, en las islas Diaoyu o Senkaku que disputa directamente a Japón; las islas Spratlys, cuyo litigio lo confronta con Taiwán, Mala-

${ }^{70}$ Cf. "Rusia y China vetan la resolución de condena a la represión siria", $E l$ Mundo, 5 de octubre de 2011.

${ }^{71}$ Cf. A. Soto, "China ante la crisis iraní”, Real Instituto Elcano, área Asia Pacífico, ARI núm. 49-2006.

72 Cf. Ch. Solomon, "Does China's Silk Road lead to Damascus?", Global Risk Insights, 5 de julio de 2016, en http:/ /globalriskinsights.com. 
sia, Filipinas, Brunei y Vietnam, mientras que el debate de la soberanía sobre las islas Paracelso la enfrenta únicamente a Vietnam. ${ }^{73}$ Por lo que se refiere al ámbito armamentista, tanto Estados Unidos como la RPch son los países que más gastan en esa área.

De otra parte, Washington y Pekín han sumado en el último lustro una nueva área de competencia, la de la influencia del ámbito económico-comercial en la región. Esta situación fue acentuada por el Tratado de Libre Comercio que entró en vigor el 1 de enero de 2010 entre la RPCh y las economías de ASEAN, ${ }^{74}$ así como por el logro, por parte de la RPCh, de una zona de libre comercio entre las economías de APEC durante la clausura de la XXII Cumbre de dicho foro celebrada en noviembre de 2014 en la capital china ${ }^{75}$ y que contrasta con el Acuerdo Transpacífico de Asociación Económica (трР, por sus siglas en inglés), cuya promoción lideró la administración de Barack Obama. ${ }^{76}$ Finalmente, en lo que se refiere al ámbito del comercio bilateral, desde finales de 2015 la RPCh se convirtió en el mayor socio comercial de Estados Unidos; ${ }^{77}$ sin embargo, a pesar del crecimiento de dichos lazos comerciales, durante la administración del presidente Obama, éstos se han vuelto cada vez más complejos, en especial porque Washington acusa a Pekín de espionaje cibernético, apoyo financiero a empresas estatales con afán proteccionista, violación constante de los Derechos de Propiedad

${ }^{73}$ A. S. Erickson, "Keeping the Near Seas Peaceful: American and Allies Mission, Asia-Pacific Interest”, en Richard Pearson (ed.), East China Sea Tensions: Perspectives and Implications, Washington, DC, The Maureen and Mike Mansfield Foundation, 2014, p. 24.

${ }^{74}$ Para la administración Obama, el TPP tenía como propósito disminuir la influencia de la RPCh en las economías del Foro de Cooperación Económica AsiaPacífico (APEC); sin embargo, el 23 de enero de 2017, con Donald Trump como nuevo presidente, Estados Unidos se retiró del acuerdo.

75 Véase El Universal, 12 de noviembre de 2014.

${ }^{76}$ Las economías incluidas en el TPP son las siguientes: Australia, Japón, Canadá, Singapur, Malasia, México, Vietnam, Perú, Brunei Darussalam, Nueva Zelanda, Chile y Estados Unidos (este último hasta el 23 de enero de 2017). Véase “Acuerdo de Asociación Transpacífico (TPP)...”, Sistema de Información de Comercio Exterior, en www.sice.oas.org/TPD/TPP/TPP_s.ASP.

77 Véase El Financiero, 8 de agosto de 2015. 
Intelectual y políticas intervencionistas para controlar el valor de su moneda. ${ }^{78}$

Como ya se ha visto, desde el nacimiento de la misma República Popular de China, la historia de la relación política entre Pekín y Washington se ha desarrollado en medio de una mezcla de encuentros y desencuentros que tienen que ver con las divergencias ideológicas, las convergencias en lo que se refiere a necesidades económicas o de seguridad, así como con las interpretaciones asumidas acerca del incremento de las capacidades materiales y la competencia que a partir de este punto se produce. Con la consideración de estos precedentes se presenta, entonces, la disyuntiva que Brooks y Wolhforth interpretan como una hegemonía sin probabilidad de equilibrio y la percepción de la amenaza que países como la RPCh representan cuando la potencia hegemónica intenta limitar lo que asume como acciones basadas en lo que concibe como su derecho.

\section{REALISMOS ESTRUCTURAL Y NEOGLÁSICO Y CONSTRUCTIVISMO EN LA ACTUAL RELACIÓN POLÍTICA SINOESTADOUNIDENSE EN Asia DEL Este}

Como ya se subrayó en el apartado anterior, la relación sinoestadounidense encierra una compleja interacción, en la cual el entendimiento de potencia hegemónica por parte de Estados Unidos y el de nación de protagonismo histórico encarnado en la RPCh encuentran puntos de convergencia en el reconocimiento de intereses comunes, así como de divergencias resultantes de la identificación de metas u objetivos que chocan en espacios específicos o por causa de la utilización de medios que producen una percepción de amenaza por ambas partes.

La interacción en la relación sinoestadounidense en Asia del Este se concentra en varios rubros como un vínculo económico de

${ }^{78}$ W. M. Morrison, "China-U.S. Trade Issues”, Congressional Research Service, CRS Report prepared for Members and Committees of Congress, 7.5700, RL33536, 24 de abril de 2017, en https://fas.org/sgp/crs/row/RL33536.pdf. 
gran trascendencia, pues cada uno supone ser para el otro el mayor socio comercial actual. Asimismo, en el ámbito político, las dos grandes potencias han cooperado en asuntos de gran relevancia regional como el trabajo conjunto para disuadir a Corea del Norte de continuar con su programa nuclear. Sin embargo, el constante crecimiento económico de la RPCh, sus reclamos territoriales frente a sus vecinos -en especial el propósito de lograr la reincorporación de Taiwán a su soberanía-, así como el incremento en su gasto militar, han puesto en alerta a Washington, que asume que dichos reclamos y formas de pretender hacerlos efectivos pueden socavar su posición en la región y afectar con ello su primacía global. Tomando en cuenta lo anterior, uno podría plantearse la siguiente pregunta: ¿el mero incremento de las capacidades materiales y su interés en alcanzar sus objetivos territoriales hace que la RPCh se convierta en el rival que desafíe la hegemonía estadounidense en Asia del Este?

Como ya se señaló en el apartado teórico, desde el punto de vista del realismo clásico o del neorrealismo podría plantearse que sólo el incremento de las capacidades materiales de un país de la magnitud de la RPCh representa un reto directo para Washington. Sin embargo, la posición por discutir se concentra en lo que Brooks y Wohlforth señalan como el estatuto del gran poder de Estados Unidos en donde un país de sus capacidades materiales no encuentra restricciones o limitaciones a su política de seguridad, la que además tiene alcance global. ${ }^{79}$

Para los realistas en general, el poder de un Estado sólo puede ser comprobado de forma efectiva por medio del contrabalance de poder, es decir con la movilización y el desarrollo de capacidades militares suficientes por parte de una o varias potencias para limitar o bloquear al Estado que detenta la primacía y evitar que el avance en la obtención de sus intereses afecte el statu quo. ${ }^{80} \mathrm{Sin}$ embargo, como ya se mencionó, Brooks y Wohlforth argumentan que entre más poderosa sea una potencia hegemónica, menos posibilidad tendrá de ser contrabalanceada. ${ }^{81}$

79 Op. cit., p. 15.

${ }^{80}$ Ibid., pp. 22 y 27.

${ }^{81}$ Ibid., p. 23. 
Respecto a lo anterior, como ya se recalcó en el primer apartado, Estados Unidos es el Estado que cuenta las mayores capacidades en todas las dimensiones de poder. ${ }^{82}$ Asimismo, la unipolaridad de Washington implica la más estratificada jerarquía. ${ }^{83}$ Por su parte, si bien es cierto que la RPch es en la actualidad la segunda economía del mundo y ha logrado avances significativos en las dimensiones de poder señaladas por Wohlforth, también lo es el hecho de que en cada una de dichas dimensiones de poder está lejos de equipararse a Estados Unidos. Por ejemplo, respecto a sus capacidades militares, se puede señalar que son de índole defensiva o, al menos, limitadas a tener un cierto alcance regional. Por lo que se refiere a sus avances tecnológicos, éstos aún se consideran como inferiores a los de los estadounidenses. Asimismo, según Wohlforth, si bien la RPCh ha mostrado crecimiento constante, tanto en su economía como en su presencia política y militar, éste se ha dado conforme al statu quo actual, es decir conforme al orden internacional liderado por Washington, de modo que, en este contexto, habría que preguntarse cuál sería el motivo por el que Pekín desearía romper con un orden que ha propiciado su crecimiento económico y, por tanto, su desarrollo. ${ }^{84}$

La perspectiva de Wohlforth y Brooks acerca de que Estados Unidos goza de una primacía sin precedentes y de que es improbable que su posición hegemónica sea afectada, cuando menos en algunas décadas, goza de mucha aceptación. ${ }^{85}$ Por ejemplo, Robert Lieber, en su planteamiento, coincide con la perspectiva de Wohlforth, cuando señala que Estados Unidos, más que cualquier otro país, tiene una capacidad preponderante y, ante la característica anárquica del sistema internacional, los demás Estados requieren su liderazgo, fundamentalmente cuando se pre-

${ }^{82}$ Geopolítica, militar, económica y tecnológica. Véase W. Wohlforth, art. cit., p. 7.

${ }^{83}$ W. Wohlforth, "Unipolarity, Status, and Great Power", World Politics, núm. 61, 2009, p. 41.

${ }^{84}$ Ibid., p. 31.

${ }^{85}$ La caída de la uRss fue una ecuación de suma cero perfecta, ya que su efecto inmediato provocó "un cambio dramático en favor de Estados Unidos". Véase K. Brooks y W. Wohlforth, op. cit., pp. 18-19. 
sentan situaciones que pueden considerarse como peligrosas o complejas. ${ }^{86}$ También Bradley Podliska concuerda con Wohlforth, Brooks y Lieber cuando señala que el poder del actual hegemón se sustenta en sus capacidades para forzar a otros y para proveer bienes de seguridad con el fin de garantizar que la economía y, en general, el orden mundial, le siga favoreciendo. ${ }^{87} \mathrm{~A}$ fin de cuentas, para un hegemón o incluso para cualquier poder creciente, la meta fundamental es mantener e incrementar sus capacidades materiales y sus esferas de influencia, una "filosofía" que ha configurado la base ideacional estadounidense desde su mismo nacimiento. ${ }^{88}$

Los planteamientos de Wohlforth, Brooks, Lieber y Podliska explican, en gran medida, la forma en que Estados Unidos actúa en la política internacional y destacan que ante la amenaza a sus intereses y, por tanto, lo que considera como su seguridad nacional, Washington, tomando en cuenta sus capacidades, debe actuar de forma unilateral en ocasiones o por medio de "entes internacionales" como coaliciones, ${ }^{89}$ instituciones internacionales o alianzas, que crea y adapta para instrumentarlas como mecanismos que complementen y, si es posible, legitimen su estrategia de seguridad. Ahora bien, si tomamos en cuenta las capacidades de Estados Unidos frente a la RPCh, que es la segunda economía del mundo y la segunda que más gasta en armamento, quedaría en evidencia su superioridad material frente al gigante asiático tal y como aparece en el cuadro de la siguiente página.

Sin embargo, si es tal la diferencia entre ambos países, ¿por qué el constante crecimiento chino respecto a sus capacidades materiales produce incertidumbre en el este asiático y en Estados Unidos, en consecuencia? y ¿qué es lo que pretende la RPch con el incremento de dichas capacidades militares en la región?

${ }^{86}$ The American Era Power and Strategy for the $21^{\text {st }}$ Century, Cambridge, University Press, 2005, p. 4.

${ }^{87}$ Acting Alone: A Scientific Study of American Hegemony and Unilateral Use-of-Force Decision Maker, Lanham, MD, Lexigton Books, 2010, p. 22.

${ }^{88}$ Ibid., p. 72.

${ }^{89}$ Ibid., p. 40. 


\begin{tabular}{|c|c|c|c|c|c|c|c|}
\hline País & $\begin{array}{c}\text { PIB (dólares } \\
\text { estadouni- } \\
\text { denses) }\end{array}$ & $\begin{array}{c}\text { Ranking PIB } \\
\text { mundial }\end{array}$ & $\begin{array}{c}\text { PIB global } \\
(\%)\end{array}$ & $\begin{array}{c}\text { Gasto militar } \\
\text { ylugar en la } \\
\text { lista general }\end{array}$ & $\begin{array}{c}\text { Cabezas } \\
\text { nucleares }\end{array}$ & $\begin{array}{c}\text { Porcentaje del } \\
\text { gasto militar } \\
\text { respecto a } \\
\text { su PIB }\end{array}$ & $\begin{array}{c}\text { Porcentaje del } \\
\text { gasto militar } \\
\text { global }\end{array}$ \\
\hline $\begin{array}{c}\text { Estados } \\
\text { Unidos }\end{array}$ & $\begin{array}{c}16800.00 \\
\text { billones }\end{array}$ & 1 & 19.31 & $\begin{array}{c}640 \text { mil } \\
\text { millones. } \\
\text { ler lugar }\end{array}$ & 7260 & 3.3 & 36.00 \\
\hline RPch & $\begin{array}{c}9240.00 \\
\text { billones }\end{array}$ & 2 & 10.15 & $\begin{array}{c}188 \text { mil } \\
\text { millones. } \\
\text { 2do lugar }\end{array}$ & 260 & 1.9 & 13.00 \\
\hline
\end{tabular}

Fuente: cuadro del autor con información de los informes del Stockholm International Peace Research Institute, abril de 2016.

Desde una perspectiva constructivista es necesario recordar la problematización de identidades e intereses, ${ }^{90}$ que las identidades son el rasgo fundamental de cada Estado, ${ }^{91}$ que éstas anteceden a los intereses $\mathrm{o},{ }^{92}$ al menos, se retroalimentan mutuamente y, en ese sentido, son la base para la acción social o política de los Estados. ${ }^{93}$ Según este argumento, es preciso señalar que desde su nacimiento, Estados Unidos se percibió como una nación cualitativamente diferente y moralmente superior, es decir excepcional. ${ }^{94}$ Según Kal Holsti, un Estado que se asume como excepcional tiene la autopercepción de que es "moralmente limpio" y que, por ello, es objeto de odio y agresión de los demás. Por esta razón desarrolla tanto la sensación de existir en un mundo hostil, como la necesidad de tener enemigos externos que justifiquen sus acciones ante lo que identifica como amenazas. ${ }^{95}$

${ }^{90}$ A. Wendt, art. cit., p. 397.

91 T. Hopf, art. cit., p. 193.

${ }^{92} \mathrm{~J}$. Weldes, art. cit., p. 275.

${ }^{93}$ R. N. Lebow, art. cit., p. 474.

94 S. M. Lipset, El excepcionalismo americano: una espada de dos filos, México, Fondo de Cultura Económica, 2000, p. 33.

95 "Exceptionalism in America Foreign policy: Is it exceptional?", European Journal of International Relations, vol. 17, núm. 3, 2011, p. 384. 
La autopercepción de ser una nación excepcional impregnó a la sociedad estadounidense que se identificó a sí misma como una "nueva nación" poseedora de un matiz "divino", con instituciones políticas y religiosas "justas y acertadas". ${ }^{96}$ Asimismo, tras el final de la Segunda Guerra Mundial, Estados Unidos quedó como potencia hegemónica y asumió para sí esta nueva identidad. Esta posición se fortaleció tras la caída de la Unión Soviética y, con ello, ratificó un orden mundial favorable para sí conforme a la idea de que Estados Unidos no sólo es el país con la mayor preponderancia en el mundo de capacidades materiales, sino también una nación cuyos valores poseen "supremacía moral" frente a los que practica el resto de la humanidad. ${ }^{97}$ Por ese motivo, uno de los principales objetivos actuales de Washington es mantener su primacía por medio de sus instituciones y valores, con el interés de confirmar el orden internacional vigente sin que "nada ni nadie" lo modifique. De esta forma, no sólo se interesa en sostener mayores capacidades materiales que el resto de las grandes potencias, sino que también trata de evitar que algunas potencias regionales, como la RPCh, puedan producir para sí mejores condiciones de competencia y ello propicie mayor involucramiento de ésta en los asuntos regionales, ${ }^{98}$ circunstancia que afectaría su influencia y limitaría el alcance del poder global estadounidense y dañaría su imagen como hegemón y su identidad como tal. De ahí el incremento de la vigilancia militar estadounidense en la región. A fin de cuentas, percibe como amenaza las demandas y acciones provenientes de la RPCh.

Si se analiza la posición china, debe tomarse en cuenta la relevancia de los resentimientos, producto de un siglo de humillación sufrida por China a manos de las potencias occidentales y de Japón, ${ }^{99}$ tal y como Yuen Foong Khong lo describe: "China es una

${ }^{96}$ P. Johnson, Estados Unidos: la historia, Buenos Aires, Javier Vergara Editor, 2002, p. 52.

97 Id.

${ }^{98}$ L. H. M. Ling, "Worlds beyond Westphalia: Daoist dialectics and the «China Threat»", Review of International Studies, núm. 39, 2013, p. 556.

${ }^{99}$ D. Kang, China Rising: Peace, Power, and Order in East Asia, Nueva York, Columbia University Press, 2007, p. 81. 
nación incapaz de olvidar". ${ }^{100}$ Pero, en esa sintonía, se tendría que considerar que las experiencias buenas o traumáticas forman parte de la identidad de cualquier nación. Sin embargo, a partir de estas experiencias, China adquirió otros atributos y características que forman parte de su identidad. Una de ellas es la valoración de algunas normas westfalianas, como el principio de soberanía, así como la apreciación de que tanto la soberanía, como la unidad, son aspectos clave de las relaciones internacionales de nuestros días. ${ }^{101}$ Por tal motivo, Pekín ha puesto gran atención en una postura que considera indisoluble: la protección de su unidad y su soberanía y, en ese sentido, su preocupación por alcanzar su integridad territorial. De igual manera, en los últimos años ha comenzado a demandar mayor influencia en los órganos internacionales relevantes. ${ }^{102}$

En lo que atañe a la visión china acerca de la posición estadounidense en Asia del Este, Foong Khong señala que Estados Unidos utiliza las reivindicaciones territoriales chinas para justificar su mayor presencia militar en la región. ${ }^{103}$ Por su parte, Wu Xinbo argumenta que la postura militar de Estados Unidos en el Pacífico Occidental está dirigida a contener la emergencia de la RPCh. ${ }^{104}$ Considerando esta percepción, durante los últimos años, los grados de alarma para Pekín se han ido incrementando si se toman en cuenta las divergencias que causan, no sólo la presencia de tropas estadounidenses en el Pacífico asiático y la vigilancia constante por parte de Washington hacia la RPCh -algo que a final de cuentas no es nuevo-, sino en especial, la directriz y las interacciones que se están produciendo a partir de dicha presencia militar y del renovado interés estadounidense en la región. Según la percepción de los actuales líderes chinos, la política es-

100 "Primacy or World Order?: The United States and China's Rise", International Security, vol. 38, núm. 3, 2013-14, p. 161.

101 D. Kang, op. cit., p. 82.

${ }^{102}$ Y. Foong Khong, art. cit., p. 159.

103 Ibid., p. 160.

104 “Agenda for a new Great Power Relationship", The Washington Quarterly, vol. 37, núm. 1, 2014, p. 72. 
tadounidense en la zona está destinada a contener a la $\operatorname{RPCh}^{105}$ y asegurar, de esta forma, la continuidad de un equilibrio de poder favorable.

La preocupación de la RPCh se relaciona con el apoyo que Washington da a Taiwán en cuanto a la venta de armamento sofisticado, así como con las declaraciones por parte de autoridades estadounidenses concernientes a asuntos internos chinos, como las protestas en el Tíbet y la región de Xinjiang, donde se acusa al régimen comunista de violar los derechos humanos de las minorías tibetanas y uigures, respectivamente. Asimismo, las disputas territoriales que el gigante asiático mantiene con varios de sus vecinos, entre ellos Japón -aliado incondicional de Estados Unidos en la región-, se suman a esta serie de disyuntivas que alimentan la desconfianza mutua, pues Pekín ve en las acciones de Washington una transgresión a su soberanía y, por tanto, percibe una amenaza a su seguridad nacional. ${ }^{106}$

Con la consideración de las divergencias entre Washington y Pekín mencionadas en el párrafo anterior, habría que plantearse entonces que más que una tendencia "casi natural" a que la mera acumulación de capacidades militares por parte de la RPCh plantee un reto hegemónico a Estados Unidos, tal y como lo señalan los realistas clásicos y los neorrealistas, o a que, por el contrario, el mencionado incremento de estas capacidades sea insuficiente para desafiar la supremacía estadounidense, como lo sustentan los realistas neoclásicos, dicho crecimiento responde a un proceso de lo que Pekín considera como una necesidad básica.

El proceso, por su parte, incluye el crecimiento económico y el desarrollo contextual que para la RPch ha traído la reforma de apertura llevada a cabo desde 1978 y en la que precisamente Estados

${ }^{105}$ K. Rudd, "The Future of U.S.-China Relations under Xi Jinping: Toward a New Framework of Constructive Realism for a Common Purpose", Asia Society Policy Institute, p. 14, en http://asiasociety.org/policy-institute/us-china-21-future-us-china-relations-under-xi-jinping.

${ }^{106}$ Ch.-yu Shih y Ch.-chiu Huang, "China's Quest for Grand Strategy: Power, National Interest, or Relational Security?”, The Chinese Journal of International Politics, vol. 1, núm. 26, 2014, p. 22. 
Unidos ha tenido gran importancia. ${ }^{107}$ Según Qin Gang, portavoz del Ministerio de Asuntos Exteriores de la RPCh, el incremento en el gasto militar de su país es concordante con su desarrollo económico. ${ }^{108}$ Lo anterior pudiera parecer una premisa realista, sin embargo la realidad es mucho más compleja. Es precisamente lo que se refiere a la necesidad básica, lo que explica el incremento de las capacidades militares chinas. Este punto se concentra en lo que los líderes chinos asumen como defensa de los intereses centrales de su país: la soberanía, la integridad territorial, la unidad nacional, así como las garantías básicas para una economía sustentable y el desarrollo social. ${ }^{109}$

Algunos especialistas occidentales, como Aaron Friedberg, critican estos planteamientos destacados del Partido Comunista Chino (PCCh), como un medio de éste para mantener el monopolio político en el país: "El PCCh ha utilizado el nacionalismo como un arma para sostener su poder al interior de la RPCh a través de la remembranza del daño hecho por los extranjeros y las acciones de éste para revertirlos". ${ }^{110}$ Asimismo, menciona que Pekín presiona a Estados Unidos en lo que se refiere a su presencia militar y busca limitar su influencia en la región para desplazarlo como potencia preponderante en Asia del Este. ${ }^{111}$ Sin embargo, Friedberg parece minimizar la memoria histórica china, ya que además de los dirigentes de la RPch, la mayoría de la población china tiene presente que la debilidad de su imperio la hizo víctima de la humillación por parte de las potencias extranjeras que entre las décadas de

${ }^{107}$ Estados Unidos desempeñó un papel fundamental en la inserción de la RPCh en la economía global al abrir su mercado a los productos chinos y permitir la inversión de las transnacionales de origen estadounidense en el conjunto de procedimientos que implementó el régimen comunista para activar la productividad al interior de su país.

108 Véase The Diplomat, 6 de marzo de 2014.

109 W. Xinbo, "Forging Sino-US Partnership in the Twenty-First Century: Oportunities and challenges", Journal of Contemporary China, vol. 12, núm. 75, 2012, p. 393.

110 "The Sources of Chinese Conduct: Explaining Beijing's Assertiveness", The Washington Quarterly, vol. 3, núm. 4, 2015, p. 138.

111 A Contest for Supremacy: China, America, and the Struggle for Mastery in Asia, Nueva York, W. W. Norton \& Company, 2011, p. 2. 
1840 y 1940 ocuparon o administraron diversos territorios del gigante asiático y, en el caso de Japón, perpetraron grandes matanzas contra la población civil entre 1937 y 1945, dejando con ello una evidente experiencia traumática para esta nación. Por tal razón, desde la misma fundación de la República Popular de China en octubre de 1949, el nuevo régimen asumió como un fundamento de la esencia del nuevo Estado, la necesidad de cuidar su soberanía y su población, así como la de recuperar los territorios perdidos, ${ }^{112}$ lo anterior con el fin de restablecer lo que considera su integridad territorial. Por otro lado, los líderes del PCCh tienen en cuenta que la incapacidad para acceder, o al menos mantener, a la actual integridad territorial y su soberanía, puede poner en duda la misma legitimidad del $\operatorname{PCCh}^{113}$ y, con ello, la existencia de la misma RPCh.

Tomando en cuenta lo anterior, es preciso señalar que las tensiones entre la RPCh y Estados Unidos en el Mar de China no son nuevas -al menos en el caso de Taiwán-, sino que se han dado desde 1949. En esa sintonía, también hay que mencionar que la RPCh, en su objetivo de lograr su integridad territorial total, ha conseguido restablecer su soberanía por la vía militar, tal y como lo hizo en Cantón en 1949, en el Tíbet, en 1950, y en Aksai-Chin frente a India, en 1962, o por medio de la negociación en Hong Kong, en 1997, y Macao, en 1999, al tiempo que definió pacíficamente sus fronteras con la URss en el Extremo Oriente, en los ríos Ussuri y Amur, en 1989, acuerdo que mantiene ahora con Rusia. Por si fuera poco, sostiene negociaciones con la mayoría de los países con los que comparte fronteras terrestres, a fin de delimitarlas. Asimismo, como ya se señaló, tiene como meta imponer su autoridad en las islas Daioyu o Senkaku, Spratlys y Paracelso.

Respecto a las disputas en el mar al sur de China, Friedberg señala que el incremento de ejercicios militares por parte de la RPCh en la zona, es clara muestra de que Pekín tiene la voluntad

112 Taiwán, Hong Kong, Macao, Cantón, Islas Spratlys, Paracelso y Diaoyu o Senkaku.

${ }^{113}$ W. Xinbo, "Forging Sino-US Partnership in the Twenty-First Century...", p. 393. 
evidente de cumplir sus amenazas y exhibir su fuerza en la competencia que ha desplegado para controlar dichas aguas, así como el espacio aéreo de la zona y tener mejor posicionamiento para dominar los recursos fuera de las costas chinas. ${ }^{114}$ Desde esta perspectiva, dichas acciones se reafirmaron con la declaración del régimen de Pekín en noviembre de 2013, acerca de la Zona de Identificación de Defensa Aérea, con lo que expandió su espacio estratégico más allá de sus aguas territoriales. ${ }^{115}$ Lo anterior puede plantear otra premisa netamente realista si se asume que las acciones chinas pueden estar dirigidas a controlar una región como un primer paso para consolidarse como la potencia en Asia del Este por encima de Estados Unidos.

Sin embargo, de nueva cuenta sería dable reflexionar acerca de si el incremento en los gastos militares o las declaraciones de los dirigentes chinos se centran en mostrar su interés por disputar la hegemonía a Estados Unidos en Asia del Este. A fin de cuentas sería demasiada responsabilidad para Pekín asumir ese papel, tal y como los líderes chinos reconocen. ${ }^{116}$ En todo caso, se tendría que considerar una serie de hechos que ha motivado la toma de decisiones en ciertas directrices por parte de las autoridades chinas, por ejemplo, la crisis del Estrecho de Taiwán en 1996, que Estados Unidos utilizó como justificación para renovar la Alianza de Defensa con Japón; la constante vigilancia aérea estadounidense, que ya provocó un incidente como el sucedido en Hainan, en abril de 2001; la declaración del presidente Obama, en 2011, acerca de que Asia-Pacífico es una prioridad para Estados Unidos, ${ }^{117}$ en una

${ }^{114}$ A. L. Friedberg, op. cit., p. 133.

115 Shi Yinhonhg, de la Universidad de Renmin en Pekín, señala que la declaración de la Zona de Identificación de Defensa Aérea es la primera que hace el régimen de Pekín desde la fundación de la RPch en 1949 en lo que atañe a expandir su espacio estratégico fuera de sus aguas territoriales. Véase G. G. Chang, "Economic Implications of Provocative Chinese Behavior in the East China Sea", en Richard Pearson (ed.), East China Sea Tensions: Perspectives and Implications, Washington, DC, The Maureen and Mike Mansfield Foundation, 2014, p. 15.

${ }^{116}$ Y. Foong Khong, art. cit., p. 172.

117 "Estados Unidos es una potencia en el (Océano) Pacífico y estamos aquí para quedarnos", declaración del presidente Obama durante la visita oficial a Australia el 16 de noviembre de 2014. Véase R. Ferreira, "EEUU envía infantes de 
clara alusión al incremento de la influencia china en la región. Asimismo, la afirmación, en 2014, por parte del mismo Obama de que las islas Senkaku o Diaoyu están amparadas por el artículo 5 del Tratado para la Cooperación y Seguridad Mutua entre Estados Unidos y Japón; ${ }^{118}$ así como las Estrategias de Seguridad Nacional presentadas por el gobierno estadounidense en mayo de 2010 (ESN 2010) y en febrero de 2015 (ESN 2015), en las que se plantea que además de procurar desarrollar una relación constructiva con la RPCh, Washington tiene como objetivos seguir de cerca el programa de modernización militar chino con el fin de garantizar que tanto sus intereses como los de sus aliados regionales y mundiales no se vean afectados de forma negativa ${ }^{119} \mathrm{y}$ establecer un monitoreo de reglas y normas internacionales en cuestiones como la seguridad marítima para el comercio y los derechos humanos. ${ }^{120}$

Las acciones de Estados Unidos mencionadas en el párrafo anterior, no sólo producen desconfianza e irritación en los dirigentes de la RPch, sino que además se las percibe como una amenaza, pues consideran que dañan sus principales intereses. ${ }^{121}$ Los líderes chinos ven en el incremento de la presencia estadounidense y su apoyo a países asiáticos con los que la RPch tiene querellas marítimas una forma de contener el avance del desarrollo chino, pues asumen que con su poder superior Washington define sus intereses nacionales a expensas de otros, incluidos

marina a Australia ante el aumento del poderío chino”, El Mundo, 17 de noviembre de 2011, en www.elmundo.es/america/2011/11/17/estados_unidos/1321564323. html.

118 "La política de Estados Unidos es clara: las islas Senkaku son administradas por Japón y por tanto están dentro del alcance del artículo 5". Véase "Obama apoya a Japón en disputa territorial con China por islas Senkaku/Diaoyu”, BBC Mundo, 23 de abril de 2014, en http://www.bbc.com/mundo/ultimas_noticias/2014/04/ 140423_ultnot_eeuu_obama_apoyo_senkaku_tsb.

119 National Security Strategy, mayo de 2010, p. 43, en http://nssarchive.us/ NSSR/2010.pdf

${ }^{120}$ National Security Strategy, febrero de 2015, p. 24, en http://nssarchive.us/ wp-content/uploads/2015/02/2015.pdf

${ }^{121}$ W. Xinbo, "Forging Sino-US Partnership in the Twenty-First Century...", p. 394. 
aquellos que para Pekín son centrales, ${ }^{122}$ como el referente a la integridad territorial.

Asimismo, el régimen de Pekín sostiene que los esfuerzos de diálogo respecto a alguna disputa territorial concierne sólo a los actores involucrados de forma directa, ${ }^{123}$ por ese motivo considera la constante intervención de Washington en asuntos fuera de su vecindario como desafiantes y dañinos para los intereses centrales chinos, tales como su propia soberanía. Por ello, los líderes del RPch consideran necesario el impulso de la modernización de su ejército para hacer frente a lo que tienen por una presión de los estadounidenses; ${ }^{124}$ lo anterior, obviamente, aprovechando el crecimiento económico que la RPCh ha tenido en las dos últimas décadas.

Como ya se señaló aquí, Weldes asume que las identidades anteceden a los intereses ${ }^{125}$ o que, en todo caso, pueden reproducirse mutuamente, y por tal motivo es claro que, tras más de un siglo de luchas internas, de humillaciones y vejaciones en las que sucumbieron millones de chinos y su territorio se vio cercenado por causa de la intervención de las potencias extranjeras, la intención del PCCh se centró en plantear como principios fundamentales la integridad territorial, la defensa de su soberanía, la unidad nacional y la estabilidad política en su misma fundación. Y para que dichas premisas tengan sustento, es evidente la necesidad de armarse, sin que ello tenga como meta emitir por fuerza una amenaza para sus vecinos o la intencionalidad de competir por la hegemonía. En todo caso, se trata de un asunto de defensa.

En el informe realizado en 2013 por el Ministerio de Defensa Nacional de la República Popular de China, se hizo hincapié en la consideración de que el crecimiento del país tiene como consecuencia la aparición de nuevos retos para la seguridad nacional y seguridad social. Lo anterior implica que con el aumento de los intereses nacionales, los ámbitos de la seguridad nacional china se

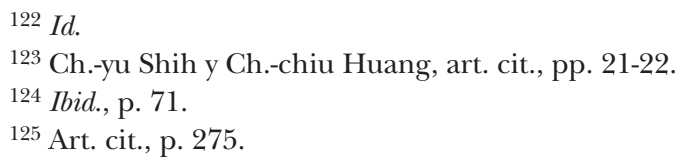


amplían y, por tanto, se vuelven más vulnerables a las confusiones regionales e internacionales. Asimismo, los líderes chinos asumen que las mayores potencias mundiales continuamente ajustan sus estrategias de seguridad nacional y sus políticas de defensa con el objetivo de potenciar sus alcances militares, lo que conlleva una serie de nuevos retos para Pekín. Por esta razón, ante el objetivo de alcanzar un crecimiento pacífico, próspero y armonioso para 2021, Pekín asume que sus fuerzas armadas deben trabajar de forma ardua si desea construir una postura estratégica favorable que garantice la seguridad y el desarrollo pacífico del país: "Sin una fortaleza militar, ningún país puede estar seguro o ser fuerte". ${ }^{126}$

Actualmente, las tareas que las fuerzas armadas chinas definen como puntos principales son las siguientes: la vigilancia de la soberanía en tierra, mar y aire; la determinación para unificar a la patria; la garantía de la seguridad y las nuevas metas de la RPch: velar por los intereses de la RPCh en el extranjero; mantener la capacidad de disuasión y, si se precisa, de contrataque nuclear; cooperar en la seguridad regional e internacional para mantener la paz; fortalecer los esfuerzos de infiltración contra el separatismo y el terrorismo a fin de mantener la seguridad política y social doméstica, así como para realizar tareas de socorro, protección a los derechos, tareas de guardia y apoyo al desarrollo socioeconómico. ${ }^{127}$

A final de cuentas, si bien es cierto que el presupuesto militar chino se ha incrementado durante los últimos años, también lo es el hecho de que los líderes de la RPch han entendido que su país está muy lejos de alcanzar las dimensiones de la infraestructura militar estadounidense, al menos en el corto plazo, por lo que se puede asentir que, la meta no es, al menos por ahora, desafiar la hegemonía de Estados Unidos; en todo caso, como ya se señaló, el objetivo de modernizar su ejército tiene dos vertientes a partir de sus identidades. La primera se refiere al planteamiento de que el poder de su ejército debe estar acorde con la magnitud de su crecimiento económico y, por tanto, con sus responsabilidades internacionales. Respecto a la segunda, si la RPCh tiene como fin la

${ }^{126}$ Ministry of National Defense. The People's Republic of China, 2013. ${ }^{127} \mathrm{Id}$. 
restauración de lo que considera su completa integridad territorial, entonces debe esforzarse por actualizar sus capacidades integrales de defensa y despliegue para estar en condiciones de hacer efectivas las demandas sobre los territorios que considera suyos, pero con la intención de evitar el conflicto, en especial si involucra a una potencia con las capacidades y el alcance de Estados Unidos.

\section{Conclusión}

La actual relación política sinoestadounidense denota gran complejidad por la serie de temas e interacciones desarrollada entre ambos países desde la misma fundación de la República Popular China a finales de 1949. La dinámica política bilateral ha pasado desde la más cruda enemistad que los llevó a confrontarse en una guerra no declarada durante el conflicto de Corea hasta la cooperación en el intercambio de información durante la década de 1980 para contrarrestar el expansionismo soviético en Asia Central y la colaboración conjunta para persuadir a Corea del Norte de seguir con su programa nuclear durante la década de 1990. Del mismo modo, la regularización de relaciones diplomáticas entre Washington y Pekín abrió las puertas a un formidable incremento del flujo comercial que hoy en día no sólo involucra a ambos Estados y los transforma en los mayores socios comerciales "el uno del otro", sino que además ha comenzado a tejer un entramado económico-financiero que también "involucra" a otras economías de la región Asia-Pacífico.

Dada la magnitud de sus capacidades, la complejidad de la relación crece si tomamos en cuenta que Estados Unidos es la máxima potencia económica y militar del mundo, mientras que la RPch se ha convertido en la segunda economía mundial y, desde hace algunos años, en el país con el segundo presupuesto del planeta empleado en gasto militar, el que ha incrementado desde 2014 en más del 10\%. Esta situación produce una aguda tensión ante la suma de discrepancias producidas por las demandas territoriales provenientes de Pekín y la renovada atención estadounidense en la región. 
Desde un punto de vista neorrealista, lo anterior puede parecer el preludio de un conflicto entre ambas potencias en Asia del Este. Desde la perspectiva del realismo neoclásico de Wohlforth y Brooks, la dinámica descrita puede plantearse como una serie de interacciones en Asia del Este, en la que, independientemente de los desacuerdos existentes entre Washington y Pekín, el statu quo permanecerá, porque las capacidades que Estados Unidos muestra en el dominio de las diferentes dimensiones de poder son tales que la RPCh tardará años en tener poder suficiente para competir por la hegemonía con los estadounidenses, además de que el gigante asiático está conforme con el orden internacional actual y lo que ello representa para la continuidad de su crecimiento económico.

Sin embargo, las distintas perspectivas realistas son indiferentes a las identidades de los Estados, que permiten entender el origen de sus intereses y, con ello, los cursos de acción que han de seguir. ${ }^{128}$ Desde una visión constructivista se puede señalar que la actual relación política sinoestadounidense en Asia del Este ofrece una oportunidad para aportar una explicación integral de la interacción política que se ha desarrollado entre ambos países en los últimos años.

En el caso de Estados Unidos, con base en sus capacidades superiores, asume su posición como potencia hegemónica y, por tal motivo, se marca como objetivo crear condiciones para la continuidad de un orden internacional que respalde dicha posición, es decir precisa mantener su preponderancia y conservar el actual statu quo, porque esta condición supone la mejor forma de asegurar sus intereses, ${ }^{129}$ entre ellos el de su seguridad nacional. Asimismo, este país identifica a la RPch como reformista-revisionista, es decir un Estado insatisfecho con el actual orden internacional porque acepta algunas reglas, pero desea limitar, introducir o modificar otras. ${ }^{130}$

${ }^{128}$ José J. Bravo Vergara y Miguel A. Sigala Gómez, “Constructivismo”, en J. A. Schiavon Uriegas, A. S. Ortega Ramírez, M. López-Vallejo Olvera y R. Velázquez (eds.), Teorías de Relaciones Internacionales en el siglo xxi. Interpretaciones críticas desde México, México, Benemérita Universidad Autónoma de Puebla et al., 2014, p. 442.

${ }^{129}$ Y. Foong Khong, art. cit., p. 166.

${ }^{130}$ X. Zhang y B. Buzan, "Correspondence: Debating China's Peaceful Rise”, The Chinese Journal of International Politics, vol. 3, 2010, p. 450. 
Si se toma en cuenta lo anterior, habría que considerar el señalamiento de Wendt acerca de que los Estados no temen al poder material en sí, sino a determinados tipos de poder. ${ }^{131}$ Por ese motivo, Estados Unidos tiene la percepción de amenaza con respecto de algunas acciones de la RPch, pues no sólo está preocupado por la magnitud en el incremento de las capacidades materiales chinas, sino también por el férreo posicionamiento del "gigante asiático" en cuanto a la aceptación de sus demandas territoriales y la ampliación de su influencia, situación que supone que podría afectar a sus aliados regionales, como Japón y Filipinas, a la vez que perjudicaría su credibilidad como potencia hegemónica y produciría un escenario en el que se vería afectado el statu quo que todavía favorece a Estados Unidos en Asia del Este.

Por su parte, más que asumir una identidad centrada sólo en el recuerdo traumático de su experiencia histórica reciente, basada en el daño perpetrado por los extranjeros entre las décadas de 1840 y 1940 , y lo que consideran como mutilación del territorio que sufrieron en la época imperial, desde su mismo ascenso al poder a finales de 1949, los dirigentes del PCCh identificaron la soberanía como un elemento central de su interés nacional y, en ese sentido, se plantearon como objetivo alcanzar lo que consideraban su integridad territorial. ${ }^{132}$ Por ese motivo, desarrollaron una dinámica dicotómica con la que han concertado acuerdos y desatado conflictos y tensiones para recuperar territorios; han obtenido algunos éxitos, pero también continuado con otros contenciosos.

Asimismo, los líderes del PCch tienen en cuenta que la legitimidad de su partido y, en cierta medida, la misma existencia de la RPCh tiene que ver con el restablecimiento de lo que consideran su territorio y la conservación de su soberanía. Por ese motivo, el régimen de Pekín percibe como una amenaza a su soberanía y, por tanto, a su seguridad nacional, el apoyo de Estados Unidos a Taiwán con la venta de armas sofisticadas o el respaldo que le otorga a Japón, Vietnam y Filipinas en aquellas disputas marítimas que sostienen con la China continental. De la misma forma, el régi-

${ }^{131}$ Art. cit., p. 397.

132 D. Kang, op. cit., p. 82. 
men chino señala que la intromisión de Washington en las disputas territoriales que Pekín mantiene con sus vecinos no debería ocurrir, porque la soberanía estadounidense no se afecta.

Finalmente, si bien es cierto que la decisión de Donald Trump de retirar a su país del TPP puede parecer algo positivo para Pekín, tal acción no modifica la hostilidad del nuevo presidente estadounidense para con la RPCh, a la que califica de competidora desleal. Esta actitud ha provocado nuevos desencuentros con el régimen de Pekín, en especial después de que tras su triunfo electoral, Trump mantuvo una conversación directa con Tsai Ing Wen, la presidenta de Taiwán, situación que perjudica la relación bilateral al poner en entredicho el convencionalismo diplomático de "Una sola China".

Es difícil identificar alguna relación política bilateral que tenga el grado de relevancia global que la que en la actualidad existe entre Estados Unidos y la RPch. Pero más que advertir que se trata de una relación netamente conflictiva donde hay una disputa inevitable por la hegemonía en Asia del Este, la relación entre ambas potencias es una mezcla de convergencias y divergencias en la que tanto Estados Unidos como la RPch actúan conforme a lo que perciben como amenaza. Ya sea al mantenimiento del actual orden internacional en el caso de Estados Unidos o al logro de metas, como el desarrollo continuo y la total integridad territorial por la parte china.

\section{Bibliografía}

Abidol, Aldo D., "Causes of the 1962 Sino-Indian War", Josef Korbel Journal of Advanced International Studies, vol. 1, 2009, pp. 74-88.

"Acuerdo de Asociación Transpacífico (TPP) - Australia, Brunei Darussalam, Canadá, Chile, Estados Unidos, Japón, Malasia, México, Nueva Zelandia, Perú, Singapur y Viet Nam", Sistema de Información de Comercio Exterior, en www.sice.oas.org/TPD/TPP/TPP_s.ASP

Adler, Emmanuel, "Seizing The Middle Ground Constructivism in World Politics", European Journal of International Relations, vol. 3, núm. 3, 1997, pp. 319-363. 
Anguiano, Eugenio, "Seguridad regional en Asia Pacífico", Anuario Asia Pacífico, núm. 4, 1997, pp. 27-69.

-, "Diplomacia de la República Popular China", en E. Anguiano (coord.), China contemporánea. La construcción de un país (desde 1949), México, El Colegio de México, 2001, pp. 179-284.

Arroyo Velasco, Rosario y Graciela Pérez Gavilán, "El conflicto chino-tibetano desde la perspectiva de la ética en Relaciones Internacionales", Revista de Relaciones Internacionales de la UNAM, núm. 91, 2003, pp. 57-67.

Bravo Vergara, José J. y Miguel A. Sigala Gómez, "Constructivismo”, en Jorge Alberto Schiavon Uriegas, Adriana Sletza Ortega Ramírez, Marcela López-Vallejo Olvera y Rafael Velázquez (eds.), Teorías de Relaciones Internacionales en el siglo XXI. Interpretaciones críticas desde México, México, Benemérita Universidad Autónoma de Puebla-El Colegio de San Luis-Universidad Autónoma de Baja California-Universidad Autónoma de Nuevo León-Universidad Popular Autónoma del Estado de Puebla, 2014, pp. 435-453.

Brooks, Kenneth y William Wohlforth, World Out of Balance: International Relations and the Challenge of American Primacy, Princenton, University Press, 2008.

Brooks, Stephen G. y William Wohlforth, "American Primacy in Perspective”, Foreign Affairs, vol. 81, núm. 4, 2002, pp. 20-33.

- y William Wolhforth, World Out of Balance: International Relations and the Challenge of American Primacy, Princenton, University Press, 2008.

Bukovansky, Mlada, "American Identity and Neutral Rights from Independence to the War of 1812”, International Organization, vol. 51, núm. 2, 1997, pp. 209-243.

Chang, Gordon G., "Economic Implications of Provocative Chinese Behavior in the East China Sea", en Richard Pearson (ed.), East China Sea Tensions: Perspectives and Implications, Washington, DC, The Maureen and Mike Mansfield Foundation, 2014, pp. 15-22.

Declaración conjunta de China y Rusia sobre el Orden Internacional en el siglo xxi, 2 de julio de 2005, en www.mfa.gov.cn/esp/zt/hjtfwelssk/t202164.htm

Erickson, Andrew S., "Keeping the Near Seas Peaceful: American and Allies Mission, Asia-Pacific Interest”, en Richard Pearson (ed.), East 
China Sea Tensions: Perspectives and Implications, Washington, DC, The Maureen and Mike Mansfield Foundation, 2014, pp. 23-30.

Ferreira, Rui, "EEUU envía infantes de marina a Australia ante el aumento del poderío chino", El Mundo, 17 de noviembre de 2011, en www. elmundo.es/america/2011/11/17/estados_unidos/1321564323. html

Foong Khong, Yuen, "Primacy or World Order?: The United States and China’s Rise”, International Security, vol. 38, núm. 3, 2013-14, pp. 153175.

Forigua-Rojas, Emersson, "Guerra en Afganistán: la experiencia soviética”, Papel Político, vol. 15, núm. 1, 2010, pp. 183-234.

Friedberg, Aaron L., A Contest for Supremacy: China, America, and the Struggle for Mastery in Asia, Nueva York, W. W. Norton \& Company, 2011.

- "The Sources of Chinese Conduct: Explaining Beijing's Assertiveness”, The Washington Quarterly, vol. 3, núm. 4, 2015, pp. 133-150.

Gaddis, John Lewis, Nueva Historia de la Guerra Fría, México, Fondo de Cultura Económica, 2011.

Garret, Banning, "US-China Relations in the Era of globalization and Terror: A framework for analysis”, Journal of Contemporary China, vol. 15, núm. 48, 2006, pp. 389-415.

Gelman, Harry, "The Soviet Far East Buildup and Soviet Risk-Taking Against China”, A project AIR FORCE report prepared for the United States Air Force, The Rand Corporation, R-2943-AF, agosto de 1982.

Gerson, Michael S., "The Sino-Soviet Border Conflict: Deterrence, Escalation, and the Threat of Nuclear War in 1969, Defense Threat Reduction Agency Advanced Systems and Concepts Office”, Report Number ASCO, 2010 027, Contract Number NOOO14-05-D-0500, 2010.

Hinton, Harold C., La China comunista en la política mundial, trad. de Ramón F. Martel, México, Unión Tipográfica Editorial Hispano Americana, 1968.

Holsti, Kal J., "Exceptionalism in America Foreign policy: Is it exceptional?”, European Journal of International Relations, vol. 17, núm. 3, 2011, pp. 381-401.

Hopf, Ted, "The Promise of Constructivism in International Relations Theory”, International Security, vol. 23, 1998, pp. 171-200.

Huang, Jing y Xiaoting Li, "China's Taiwan Policy: Dilemma and Choice”, Pacific Focus, vol. 16, núm. 2, 2001, pp. 99-114. 
Jian, Chen, China's Road to the Korean War: The Making of the Sino-American Confrontation, Nueva York, Columbia University Press, 1994.

-, China en transición. Sociedad, cultura y economía, Barcelona, Bellaterra, 2000.

Johnson, Paul, Estados Unidos: la historia, Buenos Aires, Javier Vergara Editor, 2002.

Johnston, Alastair I., "Cultural Realism and Strategy in Maoist China", en Peter Katzenstein, The Culture of National Security: Norms and Identity in World Politics, Nueva York, Columbia University Press, 1996.

Kagan, Robert, The Return of History and the End of Dreams, Nueva York, Alfred Knopf Editors, 2008.

Kang, David, China Rising: Peace, Power, and Order in East Asia, Nueva York, Columbia University Press, 2007.

Kissinger, Henry, “Obama's Foreign Policy Challenge”, Washington Post, 22 de abril de 2009.

Lebow, Richard Ned, "Identity and International Relations", International Relations, vol. 22, núm. 4, 2008, pp. 473-492.

Li, Rex, "North East Asia”, en Mary Buckley y Robert Sing (eds.), The Bush Doctrine and the War, Terrorism: Global responses, Global consequences, Nueva York, Routdlege, 2006.

Lieber, Robert, The American Era Power and Strategy for the $21^{\text {st }}$ Century, Cambridge, University Press, 2005.

Ling, L. H. M., "Worlds beyond Westphalia: Daoist dialectics and the "China Threat»", Review of International Studies, núm. 39, 2013, pp. 549-568.

Lipset, Saymour Martin, El excepcionalismo americano: una espada de dos filos, México, Fondo de Cultura Económica, 2000.

Mann, James, A History of America's Curious Relationships with China, from Nixon to Clinton, Nueva York, Vintage Books, 1998.

Morgenthau, Hans J., Politics Among Nations: The Struggle for Power and Peace, Nueva York, A. A. Knopf, 1948.

Morrison, Wayne M., "China-U.S. Trade Issues”, Congressional Research Service, CRS Report prepared for Members and Committees of Congress, 7.5700, RL33536, 24 de abril de 2017, en https:/ fas.org/sgp/ crs/row/RL33536.pdf

Nathan Andrew J. y Andrew Scobell, "How China Sees America”, Foreign Affairs, septiembre-octubre de 2012, pp. 32-47. 
National Security Strategy, mayo de 2010, en http://nssarchive.us/NSSR/ 2010.pdf

National Security Strategy, febrero de 2015, en http://nssarchive.us/wpcontent/uploads/2015/02/2015.pdf

"Obama apoya a Japón en disputa territorial con China por islas Senkaku/ Diaoyu", BBC Mundo, 23 de abril de 2014, en http://www.bbc.com/ mundo/ultimas_noticias/2014/04/140423_ultnot_eeuu_obama_ apoyo_senkaku_tsb

Oest, Kajsa Ji Noe y Peter Toft, "The Shanghai Cooperation Organization-A Threat or Opportunity for Europe?”, Institut for Statskundskab, 2007.

$\mathrm{Ou}$, Chen, “The U.S.' Political Challenges on China's National Security in the 21st Century's First Decade", Asian Social Sciense, vol. 7, núm. 6, 2011, pp. 103-109.

Podliska, Bradley, Acting Alone: A Scientific Study of American Hegemony and Unilateral Use-of-Force Decision Maker, Lanham, MD, Lexigton Books, 2010.

Powers, John, History as Propaganda: Tibetian Exiles Versus the People's Republic Of China, Nueva York, Oxford University Press, 2004.

Prozumenschikov, Mikhail Y., "The Sino-Indian Conflict, the Cuban Missile Crisis, and the Sino-Soviet Split, October 1962: New Evidence from the Russian Archives", Cold War International History Project Bulletin, 1996-1997, pp. 251-257.

Rudd, Kevin, "The Future of U.S.-China Relations under Xi Jinping: Toward a New Framework of Constructive Realism for a Common Purpose", Asia Society Policy Institute, en http://asiasociety.org/policy-institute/us-china-21-future-us-china-relations-under-xi-jinping

Ruggie, John Gerard, Constructing the World Polity: Essays on International institutionalization, Londres-Nueva York, Routledge, 1998.

"Rusia y China vetan la resolución de condena a la represión siria", $E l$ Mundo, 5 de octubre de 2011.

Santa Cruz, Arturo, Un debate teórico empiricamente ilustrado: la construcción de la soberaní japonesa, 1853-1902, Guadalajara, Universidad, 2000.

"Second Taiwan Strait Crisis Quemoy and Matsui Islands", en http:// www.globalsecurity.org/military/ops/quemoy_matsu-2.htm

Shih, Chih-yu y Chiung-chiu Huang, "China's Quest for Grand Strategy: Power, National Interest, or Relational Security?”, The Chinese Journal of International Politics, vol. 1, núm. 26, 2014, pp. 1-26. 
Shin, Hee-Suk, "U.S.-Japan Security Relations and the Politics of Northeast Asia”, Asian Perspective, vol. 20, núm. 2, 1996, pp. 333-341.

Solomon, Chris, "Does China's Silk Road lead to Damascus?”, Global Risk Insights, 5 de julio de 2016, en http:/ / globalriskinsights.com/

Soto, Augusto, "China ante la crisis iraní”, Real Instituto Elcano, área Asia Pacífico, ARI núm. 49-2006.

“Taiwan Strait I: What's Left of «One China»", ICG Asia Report No 53, Beijing/Taipei/Washington/Brussels International Crisis Group, 6 de junio de 2003.

Waltz, Kenneth, Teoría de la política internacional, trad. de Mirta Rosenberg, Buenos Aires, Grupo Editor Latinoamericano, 1988.

—, "Structural Realism after Cold War", International Security, vol. 25, núm. 1, 2000, pp. 5-41.

Welch Larson, Debora y Alexei Shevchenko, "Status Seekers: Chinese and Russian Responses to U.S. Primacy”, International Security, vol. 34, núm. 4, 2010, pp. 63-95.

Weldes, Jutta, "Constructing National Interest", European Journal of International Relations, vol. 2, núm. 3, 1996, pp. 275-318.

Wendt, Alexander, "Anarchy is what States Make of it: The Social Construction of Power Politics", International Organizations, vol. 46, núm. 2, 1992, pp. 391-425.

Wie-cheng Wang, Vincent, "Bill Clinton's «Three Noes» and Taiwan's Future”, en Winston L. Yang y Deborah A. Brown (eds.), Across the Taiwan Strait: Exchanges, Conflicts and Negotiations, Jamaica, NY, Center of Asian Studies, St. John's University, 1999, pp. 253-303.

Wohlforth, William, "The Stability of Unipolar World”, International Security, vol. 24, núm. 1, 1999, pp. 5-41.

- "Unipolarity, Status, and Great Power", World Politics, núm. 61, 2009, pp. 28-57.

Xinbo, Wu, "Forging Sino-US Partnership in the Twenty-First Century: Oportunities and challenges", Journal of Contemporary China, vol. 12, núm. 75, 2012, pp. 391-407.

—, "Agenda for a new Great Power Relationship", The Washington Quarterly, vol. 37, núm. 1, 2014, pp. 65-78.

Yuan, Jing-dong, "Sino-Russian Confidence building Measures: A Preliminary Analysis”, Working Paper No 20, enero de 1998, pp. 1-20. 
Zhang, Jiang, "China's new Foreign Policy under Xi Jinping: towards «Peaceful Rise 2.0»", Pacifica Review: Peace, Security E Global Change, vol. 27, núm. 1, 2013, pp. 5-6.

Zhang, Xioaming y Barry Buzan, "Correspondence: Debating China's Peaceful Rise", The Chinese Journal of International Politics, vol. 3, 2010, pp. $447-460$. 